\title{
A CRITICAL ASSESSMENT OF WORKFORCE DIVERSITY MANAGEMENT STRATEGIES ON FIRMS PRODUCTIVITY: A STUDY OF SOME SELECTED FOOD AND BEVERAGE INDUSTRIES IN LAGOS STATE, NIGERIA.
}

\author{
OYEDELE,Ola Olusegun ${ }^{1}$, ISSA Abdulraheem ${ }^{2}, \mathrm{ABU}_{\text {Zakeri }}{ }^{3}$ \\ Department of Business and Entrepreneurship, School of Business and Governance, Kwara State University, \\ Malete $^{1,2,3}$ \\ Email:olacollins2014@gmail.com \\ DOI: 10.36108/ljerhrm/8102.01.0111
}

\begin{abstract}
Workforce diversity management is gradually being used and becoming acceptable as a significant organizational resource in esteems to whether the objective is to be an employer choice, to offer outstanding customer service, or to sustain a competitive advantage.This study examined the effectof workforce diversity management towards organizational performance which focuses into the food and beverage industry within the larger manufacturing sector. The study employed primary data mainly for revalidation of results and inferential information from secondary sources. The study adopted cross sectional research design and considered 3 multinational corporations in the food and beverage sector in Nigeria based on random sampling technique. The sample size constituted the lower, middle and senior level staff of the multinational Corporations at their headquarters and plants to achieve the objectives of this study based on the two hypotheses that were formulated. Both descriptive and inferential statistical techniques were employed. The statistical tools used included cross tabulations, Mean, Regression and Correlation analysis with the aid of SPSS computer packages. The results showed that leadership initiatives (LI) has a significant relationship with organizational success $(O S)($ at $P=0.000)$. It was also observed that organizational creativity $(\mathrm{OCr})$ has significant effect on organizational creativity $(\mathrm{OCr})($ at $P=0.000)$.In conclusion, the study reflected that Workforce diversity represents both a challenge and an opportunity for business and corporate entity. Hence, no organization in this dispensation of Globalization can survive without workforce Diversity.
\end{abstract}

Keywords: Workforce Diversity Management, Leadership Initiatives, Organizational Creativity, Success Firms Productivity

\section{Introduction}

Firms are seeing the need to hire a workforce that reflects today's diverse society and a major competitive factor for organisations is attracting and retaining the best available human resource talents in the context of current workforce demographic trends (Prietto, Phipps, \&Osiri, 2009). If firms use their diverse human resources in the right way, then it will be very profitable for them because human diversity increases the flow of new, creative and innovative ideas (Afzal, Mahmood \& Sajid, 2013). According to (Richard, Barnet, Dwyer and Chandwick, 2007), diversity is more conducive to performance in the service industry where firm members come into contact with customers who prefer to be served and interact with similar others, than in manufacturing industry. Diverse workforce ensures a high level of performance and productivity for human and intellectual capital and provides business organisations a competitive advantage in their expanded markets (Okoro\& Washington, 2012). Organisations will only be successful to the extent that they are able to embrace and encourage workforce diversity (Gupta, 2013). Workplace diversity can also generate conflicts between employees. These conflicts occur due to differences of perception, ideas, behaviors, interest, attitudes, religious and political differences and unjustified distribution of resources (1said, 2012).

Workforce diversity is the issue of people;it focuses on the differences and similarities that people bring into an organisation. We all live in an increasingly multicultural society. Successful organisations recognize the need for immediate action and are ready and willing to spend resources on managing diversity in the world of work.

Leadership of organisation in the past had paid lip-services as far as work force diversity is concerned forgetting that, it is upon this pedestal that the success of business firms within local and international terrain could easily finds its footing in achieving organisational success. Mentoring programs for employees by leaders which should include feedback channels are not installed and the implementation of diversity programs which requires leaders to inspire the workforce are conspicuously missing, hence, the view of Weatling (2000) brought to bare in this study.

Finally, diverse team through intense and continuous creativity to produce better organisational results, outcomes and product quality are evasive. Business organisations are increasingly embracing the use of work groups as a 
strategy-structure mix in the pursuit organisational goals. This new trend in organizing work is predicated on flexibility, innovation, and quick decision making prospects inherent in a team-work setting. In a climate of increasing competitiveness, many organisations rely on workgroups to generate innovations necessary for sustained business success. (West\& Anderson, 1996, Mumford \& Licuana, 2004).

In line with the objectives of this study which aimed at a critical assessment of workforce diversity management strategies on firms productivity, the following hypothesesindicated in their null are postulated between workforce diversity management strategies andfirms productivity.

\section{Hypotheses One}

$\mathrm{Ho}_{1}$ : There is no significant effect of leadership initiative on organizational success. $\mathrm{Ho}_{2}$ :There is no significant effect of organizational creativity on product quality

\section{.2.Literature Review}

\subsection{Conceptual Framework}

Workforce diversity is simply how diverse is the workforce. According to Okoro and Washington (2012) "workforce diversity ensures a high level of performance and productivity for human and intellectual capital and provides business organisations a competitive advantage in their expanded markets. Organisations will only be successful to the extent that they are able to embrace and encourage workforce diversity (Gupta, 2013). Workforce diversity management is broadly defined as the systematic and planned commitment by the organisation to recruit, reward and promote a heterogeneous mix of employees (Bagshaw, 2004). Workforce diversity emerged mainly to further the availability equal opportunity philosophy is aimed at ensuring that the organisation make the most out of the differences from a diverse workforce rather than losing talent which might assist the organisation to be more efficient and effective (Bryan, 1999).The effectiveness of an organisation can be measured with different criteria (French, Wendell \& Cencil, 1983) among them is productivity, profits, growth, turnover, stability and cohesion.

\section{Leadership Initiatives in Workforce Diversity Management}

The leadership of an organisation is tasked with the responsibility of initiating and leading the dynamics of the organisation, fostering desired behaviours and ensuring that their policies and practices support the vision of the organisation while being responsive to change. In managing diverse workforce, the leader should communicate. The changing workforce is one of the challenges faced by organisations in the recent, past and most companies are not giving lip services as far as workforce diversity is concerned (Wentling, 2000). Additional benefits are also realized when the leadership of firm is diverse. Effective method of leadership development can enhance organisational productivity, profitability and responsiveness to performance if applied to a good number of persons in an organisation. A management leadership is considered to be an element of an effective diversification strategy of a company (Marquis, Lim, Scott, Harrel \& Kavanagh, 2008).

Leaders in organisations are coming up with goals for diversity strategy, which are not limited to employees only but extended to stakeholders and the public. The leaders are expected to communicate the strategies and talk about the business goals and achievement in relation to the management of workforce diversity for the strategies identified and the company as a whole (McArthur, 2010). While implementing the laid strategies, employees should be held accountable for their behaviours especially in diversity promoting behaviours that are adopted by the organisation. Some companies have articulated diversity model behaviors for their employees in which leaders lead by example in order to give guidance and direction to the rest for the realization of company goals (Code, 2007). The employees and all the stakeholders of the organisation must internalize the goals, including the public in general; where leaders place value on diversity, they initiate programs to manage the diversity. Model behaviors like conducting team building activities, rewarding employees for innovation and flexibility, encouraging employees to take ownership of ideas becoming part of the leaders' projects within organisations (Code, 2007). These leaders also ensure that their recruiting, hiring and promotion systems consider workforce diversity among other criteria followed.

Other initiative that leaders can adopt as shared by Wentling (2000) include having non- traditional work arrangement that can allow extra time and homework stations, training programs that aim to reduce stereotypes, increased cultural sensitivity within the company and developing programs that develop skills for working in a multicultural environment. Mentoring programs should be included for new employees and feedback channels installed. Implementation of diversity requires leaders to inspire their employees to own the company's goals 
objectives and in their commitment to achieve the goals, the employees embrace diversity of workforce (OSP, 2008). In embracing workforce diversity, the diversity initiatives can be grouped into fire categories (GottFredson, 1992). These are procedures to reduce ethnic and gender differences in companies, procedures to accommodate immigrants into a company, adopting changes in organisational structure to value and utilize the diversity in workforce, changes in procedures' or climate to a accommodate individual differences among employees and decentralizing problem solving to accommodate local idea and conditions. This involves leaders who are involved with their employees, communicating organisations purpose while inspiring enthusiasm and commitment of employees to perform (OSP, 2008). The OSP identifies the first step to transforming and organisation to a diverse one is creating an inclusive environment that provides a conducive working environment to all.

The US NRC advices that leaders should allow qualified employees to participate in leadership and development programs that seek to improve their skills. The staff should also be provided with meaningful career planning, mentoring and developmental opportunities for exposure and hold focus groups to determine where there are major concerns within the organisation. The managers should be able to identify and address diversity issues that arise and are considered barriers to development. Holt(2010) posits that in whatever initiative a leader will adopt, it is prudent to effectively communicate the diversity plan to employees can lead to frustrations when implementing it. The staff will get on board to contribute in achieving the set diversity plan goal. A great leader needs to come up with a list of what is to be achieved and laid down method of achieving them.

Other examples of initiatives benefiting employees are; engaging in long term planning, avoiding discrimination in hiring and compensating, implementing a code of conduct, ethic training programs, incorporating integrity in employees performance evaluations, supporting employees training and education and work-family programs (Grow, Hamm \& Lee, 2005)

\section{Organisational Creativity and Product Quality}

In an increasingly competitive environment, factors such as innovation and quality management can lead to competitive advantage. A recent survey of the Boston Consulting Group found that innovation was among the top three strategic priorities for $71 \%$ of companies (Slater, Mohr, \& Sengupta, 2014). This is in part due to innovation's being able to provide unique products and processes which create greater value for consumers as well as financial benefits for the organisation (Kim, Kumar \&Kumar, 2012).Other research suggests quality management is a known driver of innovation in organisations. Quality management practices have also been associated with operational and financial performance allowing firms to achieve a sustainable competitive advantage. As above creativity has been argued to be essential for societal and economic growth (Florida, 2004), and has been suggested to be a key factor needed to address our 21st century business challenges (Dragoon, 2010). In a 2010 global survey of more than 1500 CEOs conducted by IBM, creativity was rated as the most important leadership factor for an organisation's future effectiveness and success. Creativity always has been considered to be important in the arts, creative industries, research and development, and for knowledge workers. Recently however, organisations across industries that are not traditionally considered to be creative are starting to value creativity, and recognize that creativity can be required in any job (Shalley et al. 2000). Thus, managers have begun to seek ways to enhance, enable, and support employee creativity. To this end, creativity is often considered to be an important resource that can occur at the individual, team, and organisational level (Woodman et al. 1993). Furthermore, there is research supporting the argument that creativity can emanate from all levels of the organisation (Shalley et al. 2000).

The study of creativity has evolved significantly, from its early years of focusing on the "creative person," such as Nobel laureates and inventors (Simonton 1975; Zuckerman 1977), to examining factors in the work environment that can enhance or constrain creativity (Amabile, 1988; Tierney \& Farmer 2002). Over the last thirty years, there has been a growing body of work on organisational creativity that seeks to understand how social and contextual conditions affect both individual and team creativity (Gilson et al. 2015; Perry-Smith \& Shalley 2014;Tierney \& Farmer 2004).In the organisational creativity literature, the term creativity is used to describe both outcomes and processes. To date, most, but not all of the organisational literature examines creativity in terms of outcomes, often called creative products, ideas, or solutions that are described as being "novel, and potentially useful" (Shalley et al. 2004). However, creative outcomes and other effectiveness outcomes also are recognized to arise as the result of distinct creative processes, and these processes are proposed as a separate and distinct form of creativity. In other words, creativity encompasses both the processes of developing novel and useful ideas as well as the production of new and appropriate outcomes that then can be leveraged toward innovation.

Teasing these concepts apart, when considered as an outcome, creativity encompasses the extent to which ideas generated, solutions proposed, or products developed are both novel and useful in a particular context (Amabile 
1988; Shalley 1991). To determine the creativity of an outcome, ideas, solutions, or products are often rated by subject matter experts (Amabile 1996), supervisors (Shin \& Zhou 2003), or through objective measures such as the existence of research reports (Tierney et al. 1999), patents (Oldham \& Cummings 1996), or the number of ideas generated (Goncalo \& Staw 2006). In other words, an outcome that exists in various forms including plans, designs, budgets and products, regardless of the type of work, can be rated as creative.Creative processes as a phenomenon encompasses the 'doing' whereby individuals (or teams) behaviorally, cognitively and emotionally define problems, generate ideas, and attempt new or different ways of going about their work (Gilson \& Shalley, 2004). Therefore, creative processes are a collection of cognitive and behavioral steps that involve problem identification, searching broadly for diverse information, seeking out new approaches, linking ideas from multiple sources, generating solutions, and elaborating on the ideas developed. Furthermore, creative processes tend to be iterative, in that they do not need to adhere to or follow a prescribed or linear path.

In the global competitive business environment, employee creativity has been regarded as the building block for organisational innovation, which enhances an organisation's adaptability and growth (Tierney et al., 1999). As individual creativity is often enacted in a team context (Shalley, Zhou, \& Oldham, 2004), it is critical to understand theoretically and empirically how a member's social exchange relationships in his or her team, with both leader and teammates, simultaneously impinge on the member's creativity. If both forms of social exchange relationships make unique contributions to employee creativity, then research and practice focusing only on one form of relationship will result in an incomplete understanding of the social exchange dynamics within a team, thereby neglecting the additional resources and support conducive to team members' creativity development.Kimes (2001) was of the opinion that quality has long been a mantra of the U.S lodging industry. In her studies, she maintained that countless hotel properties have spent time and money on quality assurance, benchmarking, assessing the cost of error, continuous improvement, and total quality management among other quality-related programmes and tactics. She affirmed that most quality-assurance endeavours, however seemed to assume that quality would necessarily improve profitability. On the other hand, she maintained that quality does not always have a direct impact on return on investment (ROI), the increase on market share may indirectly influence ROI. However, researchers have found strong link among financial performance, product and service quality, and customer satisfaction at the corporate level.

\section{Social Role Theory}

Social Role Theory (SRT) is grounded on the notion that one is action; behaviours dispositions and desires are determined by a set of specific socially determined roles.

Social Role Theory constructs a set of socially acceptable norms and expectation that people internalize as they become socialized. People can then chose to either validate those norms or act against them (Eagly, 1987, Eagly\& Wood, 2012).

\section{Authoritative Roles}

SRT also points out that distribution of power and authority within society is a matter of tradition. In some cultures ones age determine authority while in the other, younger people will take over position of authority after others reach a certain age.

\section{Role Switching}

Throughout one's life one can play a variety of roles, determined by the expectations and social contexts in which one finds oneself. At work a person can play the role of boss or subordinate based upon which co-worker the person is interacting with, just as a person can play the role of drinking badly with friends in a bar and then home to play wife for a husband.

\section{Stereotypes}

Stereotypes are largely the result of expectations. A stereotype is usually the result of preconception developed on the basis of discriminatory attitudes. One can "act out" a stereotype, but then one is not functioning within a particular social role, but obviously "acting". Generally, roles are legitimate when they are married to functions.

\subsection{Empirical Findings}

Workforce diversity refers to policies and practices that seek to include people within a workforce who are considered to be in some way, different from those in the prevailing constituency. In context, here is a quick overview of scholastic contribution on the subject matter.

The information and decision making perspective is presented by Cox \& Blake (1991), who proposed this perspective as a theoretical means of understanding the links between organisational diversity and organisational 
effectiveness. They observed that up to that time, the literature available had asserted a link between organisational diversity and organisational effectiveness (and some studies had demonstrated this link using field studies of empirical finding) (Cox \& Blake 1991). However, some of these studies had actually proposed or tested a casual mechanism associated with this link, instead of leaving this issue open to interpretation. The information processing and decision making perspective effectively encapsulates the cognitive resource diversity theory, which posits that the cognitive resources of each team member contributes to the overall success of the team; therefore, a diversity of the cognitive resources promote creativity and decision making capacity (Horwitz, 2005). Cox \&Blake (1991) proposed that cultural diversity would impact six direct aspect of organisational effectiveness including the capability to attract human resources, cost, the issues of innovation, creativity and problem solving, the marketing advantages of a diverse workforce, and organisational flexibility. These six elements were revealed in terms of the major literature of the period. For the information and decision making perspective, the most relevant domain studied by the authors were innovation and creativity, problem solving capacity, and organisational flexibility. The authors' argument regarding these three perspectives can be summarized as follows.

Creativity and innovation can be aided by "diversity of perspectives and less emphasis on conformity to the norms of the past" (Cox \& Blake, 1991). This will increase ability of the organisation to create and innovate. The problem solving argument holds that better decisions would be produced through more perspective inherent in heterogeneousproblem solving groups. Finally, the flexibility argument indicate that multicultural management practices would result in changes that meant "that the system will become less determinant, less standardized, and therefore more fluid" (Cox \& Blake, 1991).these changes are likely to increase the ability of the organisation to react to changing environments.

\section{Methodology}

The study adopted descriptive survey with a structured questionnaire developed to gather information from four hundred (400) employees from top three companies in the food and beverages industries in Lagos. The population for this study comprised of strategic top management cadre, middle level staff and the lower cadre/ staff of the top three leading food and beverage firms in Lagos State, ranging from UAC foods Nig. Plc, Cadbury Nig. Plc and Nestle Nig. Plc.A combination of simple random sampling and convenience sampling techniques was adopted in determining the sample size of four hundred (400) employees from the entire population of one thousand, nine hundred and ninety nine (1999) of the three (3) major food and beverage firms in Lagos using Slovin, (1992) method of sample size determination.

Out of four hundred (400) questionnaires administered three hundred and seventy (370) representing $92.5 \%$ return and properly filled and analyzed. The study had a scale that comprised of 20 items developed by the researcher from reviewed literature and was validated. Efforts were made to ensure that respondents to the research instrument understand what the instrument wanted from them. Multiple regression and correlation analysis were the statistical tools adopted for analysis with the use of SPSS 15.0. However, the regression analysis was used to determine the cause and effect relationship that existed between workforce diversity and organisational performance. The reliability test indicated a Cronbach's Alpha of 0.6535 .

\subsection{Descriptive analysis}

\section{Demographic Characteristics of Respondents}

The respondents were asked to respond to a series of questions about themselves and the organization.

The frequency distribution of the respondents' demographic characteristics is presented in table 4.2 below. The table shows that out of the three hundred and seventy (370) respondents, $196(53.0 \%)$ are male, while 174 $(47.0 \%)$ are female. By implication, we have more male respondents to female respondents in the sample. Also, there are 70 M.Sc and M.BA holders (18.9 per cent), 15 HND/BSc holders (4.1 per cent), 35 PGD holder (9.5 per cent), in the sample 167 (18.1) and $\mathrm{PhD} 183$ (49.5). By implication, the respondents have high BSc educational qualifications.

In addition, 15 employees $(4.1 \%)$ have worked in the organizations between 1 - 5years, $6-10 y e a r s 110$ (29percent), 11 -15years 137 (37percent), 16 -20years 92 employees (24.9percent) and above $20 y e a r s 16$ employees (4.3percent). Again, out of the three hundred and seventy (370)respondents, 48 (13percent) 51 years and above, $180(48.9 \%)$ are between 41 and 50 years of age, 133 (35.9\%) are between 31 and 40 years, and 9 (2.4) are between 20 and 30 years. By implication most of the respondents are between the age of 41 and 50 years. 
More importantly, out of the 370 respondents, 129 (34.6\%) are top level managers; 191 (51.6\%) are middle level managers while $50(13.5 \%)$ are lower level managers. By implication, we have more of middle level managers as respondents in the sample.

Table 1: Frequency Distribution of the Respondents' Demographic Characteristics $(\mathbf{N}=370)$

\begin{tabular}{|c|c|c|c|c|}
\hline Characteristics & Category & Frequency & Percent & Cumulative percent \\
\hline \multirow[t]{2}{*}{ Gender } & Male & 196 & 53.0 & 53.0 \\
\hline & Female & 174 & 47.0 & 100.0 \\
\hline \multirow[t]{5}{*}{$\begin{array}{l}\text { Educational } \\
\text { Qualification }\end{array}$} & $\mathrm{BSC}$ & 15 & 4.1 & 4.1 \\
\hline & $\mathrm{BSc}$ & 35 & 9.5 & 13.5 \\
\hline & $\mathrm{MSC} / \mathrm{MBA}$ & 70 & 18.9 & 32.4 \\
\hline & PHD & 183 & 49.5 & 81.9 \\
\hline & OTHERS & 167 & 18.1 & 100 \\
\hline \multirow[t]{4}{*}{ Age } & $20-30$ & 9 & 2.4 & 2.4 \\
\hline & $31-40$ & 133 & 35.9 & 38.4 \\
\hline & $41-50$ & 180 & 48.9 & 87.0 \\
\hline & $51-60$ years above & 48 & 13.0 & 100.0 \\
\hline \multirow[t]{5}{*}{ Period of Service } & $1-5$ years & 15 & 4.1 & 4.1 \\
\hline & 6 -10years & 110 & 29.2 & 33.8 \\
\hline & $11-15$ years & 137 & 37.0 & 70.8 \\
\hline & 16 -20years & 92 & 24.9 & 95.7 \\
\hline & Above 20years & 16 & 4.3 & 100.0 \\
\hline \multirow[t]{3}{*}{ Management Cadre } & Lower level & 50 & 13.5 & 13.5 \\
\hline & Middle level & 191 & 51.6 & 65.1 \\
\hline & Top level & 129 & 34.6 & 100.0 \\
\hline
\end{tabular}

Source: Author's Fieldwork Computation, 2017

\section{Statistical Testing of Hypotheses}

\section{Test of Normality}

A normal curve could be drawn to test for normality of the dependent variable (i.e. organizational effectiveness coefficient which are represented by organizational success and product quality). Fig 4.4.1.1 to 4.4.1.4 presents a normal curve of organisational performance co-efficient scores. Many of the parametric statistics assume that the scores on each of the variables are normally distributed (i.e. follow the shape of the normal curve). In this study, the scores are reasonably normally distributed, with most scores occurring in the centre, appearing out towards the extremes.

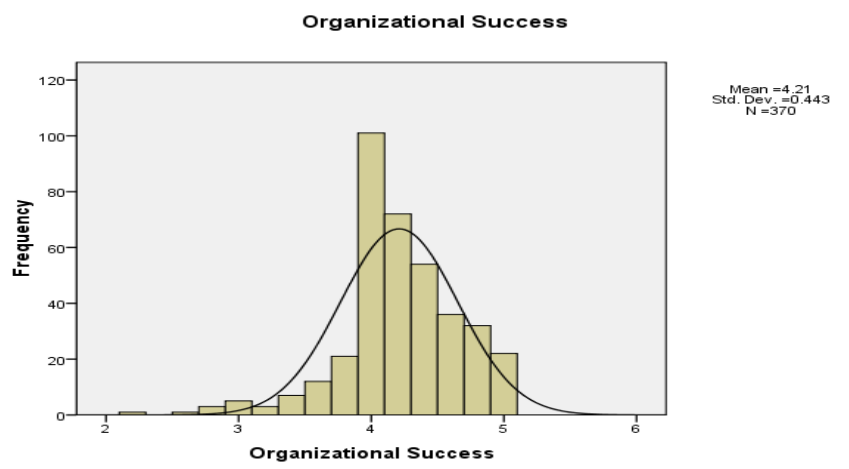

Fig 4.4.1.3: Histogram of Perceived organizational success Scores Source: Author's Fieldwork Computation, 2017 


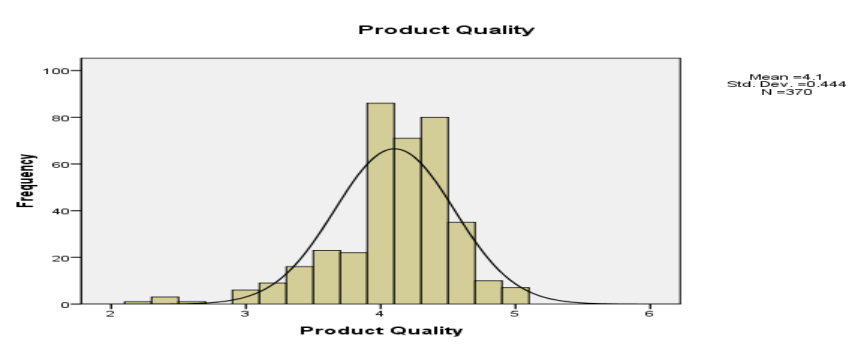

Fig 4.4.1.4 Histogram of Perceived product quality Scores Source: Author's Fieldwork Computation, 2017

Test of Multicollinearity

Multicollinearity exists when the independent variables are highly correlated (that is $r=.7$ and above). Tabachnick and Fidell (2001) suggested that you 'think carefully before including two variables with a bivariate correlation of, 0.7 or more in the same analyses. There is need to consider omitting one of the variables. To check for multicollinearity, bivariate correlation was conducted in Table 4.3 below. In the table, the highest correlation was .460. It shows low multicollinearity problem among Workforce Diversity variables (leadership initiatives and organizational creativity). Therefore, all the variables are retained.

\begin{tabular}{|l|l|c|c|}
\hline \multicolumn{3}{|l|}{ Table 4.4.2.1:Correlations among Workforce Diversity Variables } \\
\hline \multirow{3}{*}{$\begin{array}{l}\text { Leadership } \\
\text { Initiatives }\end{array}$} & Pearson Correlation & Leadership Initiatives & Organisational Creativity \\
\cline { 2 - 4 } & Sig. (2-tailed) & & 0.460 \\
\cline { 2 - 4 } & $\mathrm{N}$ & 370 & .000 \\
\hline \multirow{3}{*}{$\begin{array}{l}\text { Organisational } \\
\text { Creativity }\end{array}$} & Pearson Correlation & $.460^{* *}$ & 370 \\
\cline { 2 - 4 } & Sig. (2-tailed) & .000 & 1 \\
& & & \\
\cline { 2 - 4 } & $\mathrm{N}$ & 370 & 370 \\
\hline **. Correlation is significant at the 0.01 level (2-tailed). & \\
\hline
\end{tabular}

\section{Test of Homoscedasticity and Linearity for hypothesis one}

From the output below, there appears to be a moderate, positive correlation among the variables. Respondents that are highly affected by leadership initiatives experience low levels of organisational success. On the other hand, employees which are less affected by leadership initiatives brings about higher levels of organisational success. There is no indication of a curvilinear relationship (test of linearity) and the scatter plot shows a fairly even cigar shape along its length (test of Homoscedasticity).

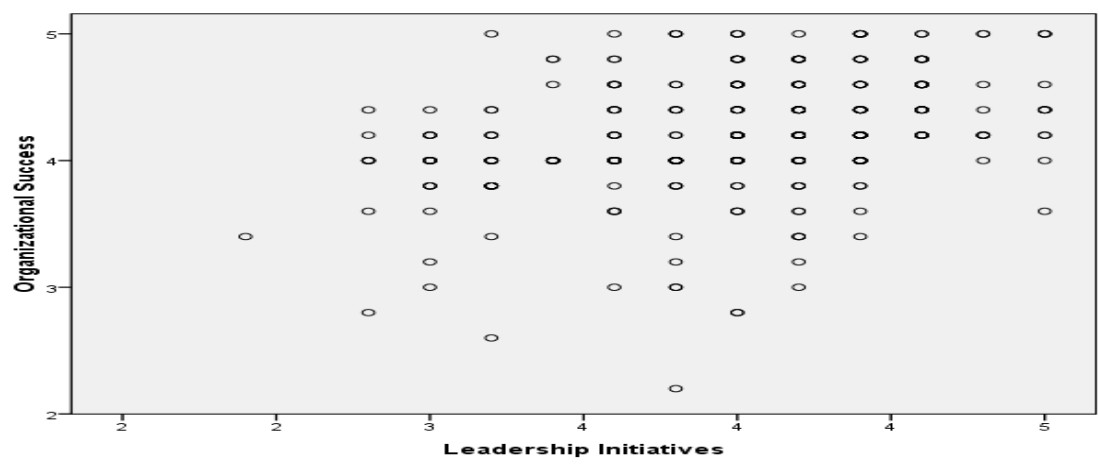

Fig 4.4.5.3.: Scatter Plot of leadership initiatives and organisational success Scores

Source: Authors Fieldwork Computation, 2017

\section{Test for Hypothesis One}

$\mathrm{Ho}_{1}$ : here is no significant effect of organisational creativity on organisational success. 
Standard multiple regression was used to explore the effect of organisational creativity on organisational success. The result of regression as contained in Table 4.4.: ANOVA, shows that the F-test was 37.073, significant at 1 percent $[p<.000]$. This showed that the model was well specified.

Table 1 Anova of organizational creativity and organizational success

\begin{tabular}{|c|c|c|c|c|c|c|}
\hline \multicolumn{7}{|c|}{ ANOVA $^{\mathbf{b}}$} \\
\hline \multicolumn{2}{|c|}{ Model } & Sum of & Df & Mean Square & $\mathrm{F}$ & Sig. \\
\hline \multirow[t]{3}{*}{1} & Regression & 20.894 & 4 & 5.223 & 37.073 & $.000^{\mathrm{a}}$ \\
\hline & Residual & 51.427 & 365 & .141 & & \\
\hline & Total & 72.321 & 369 & & & \\
\hline \multicolumn{7}{|c|}{$\begin{array}{l}\text { a. Predictors: (Constant),monetary incentives, social network, leadership initiatives and leadership } \\
\text { skills }\end{array}$} \\
\hline \multicolumn{4}{|c|}{ b. Dependent Variable: Organisational Success. } & & & \\
\hline
\end{tabular}

Authors Fieldwork Computation, 2017

Also, the result of regression as contained in Table 1Model Summary, shows that the R Square gave a large value of 28.9 per cent. This means that the model (which includes monetary incentives, social network, leadership initiatives and leadership skills) explained about 28.9 per cent of the variance in perceived organisational success.

Table 2

\begin{tabular}{|l|c|r|r|rc|}
\hline \multicolumn{6}{|c|}{ Model Summary } \\
\hline Model & $\mathrm{R}$ & \multicolumn{1}{|c|}{ R Square } & Adjusted R Square & $\begin{array}{c}\text { Std. Error of the } \\
\text { Estimate }\end{array}$ \\
\hline 1 & $.537^{\mathrm{a}}$ & .289 & .281 & .375 \\
\hline $\begin{array}{l}\text { a. Predictors: (Constant), monetary incentives, social network, leadership initiatives and leadership } \\
\text { skills }\end{array}$ \\
\hline
\end{tabular}

Authors Fieldwork Computation, 2017

Specifically, the result of regression as contained in Table 2Regression Coefficients, tests the first hypothesis of this study. From the output below, there was no positive relationship between perceived monetary incentives and organisational success such that a unit increase in perceived monetary incentives scores caused about 392 unit decreases in perceived organisational success scores which was statistically not significant at 1 per cent with the aid of the $\mathrm{p}$ value (0.062). Based on the result, the null hypothesis is accepted; thus, there was no relationship between monetary incentives and organisational success.

Also, although, there was positive relationship between social network and perceived organisational success such that a unit rise in perceived social network scores induced about .226 unit rise in perceived organisational success scores which was statistically significant at 1 per cent going by the $p$ value $(0.000)$. Based on the result, the null hypothesis is accepted; thus social network affects organisational success.

More importantly, there was positive relationship between leadership initiatives and perceived organisational success such that a unit rise in perceived leadership initiatives scores induced about .093 unit increase in perceived organisational success scores which is statistically significant at 1 per cent going by the $p$ value $(0.000)$. Based on the result, the null hypothesis is rejected; thus, there was relationship between leadership initiatives and perceived organisational success.

Furthermore, relationship between perceived leadership skills and perceived organisational success was shown in below table such that a unit rise in perceived leadership skills scores induced about .-007 unit decrease in perceived organisational success scores which was statistically not significant at 1 per cent going by the $p$ value (0.889). Based on the result, the null hypothesis is accepted; thus leadership skills did not affect perceived organisational success. 
Table 2: Coefficient table

\begin{tabular}{|c|c|c|c|c|c|c|}
\hline \multicolumn{7}{|c|}{ Coefficients $^{\mathrm{a}}$} \\
\hline \multirow{2}{*}{\multicolumn{2}{|c|}{ Model }} & \multicolumn{2}{|c|}{ Unstandardized Coefficients } & \multirow{2}{*}{$\begin{array}{c}\begin{array}{c}\text { Standardized } \\
\text { Coefficients }\end{array} \\
\text { Beta } \\
\end{array}$} & \multirow[t]{2}{*}{$\mathrm{T}$} & \multirow[t]{2}{*}{ Sig. } \\
\hline & & B & Std. Error & & & \\
\hline \multirow[t]{5}{*}{1} & (Constant) & 1.254 & .246 & & 5.089 & .000 \\
\hline & Monetary incentives & .390 & .060 & .345 & 6.536 & .062 \\
\hline & Social network & .226 & .052 & .225 & 4.315 & .000 \\
\hline & Leadership Initiatives & .093 & .046 & .108 & 2.014 & .005 \\
\hline & Leadership skills & -.007 & .050 & -.008 & -.139 & .889 \\
\hline \multicolumn{3}{|c|}{ a. Dependent Variable: Organisational Success } & & & & \\
\hline
\end{tabular}

Author's Fieldwork Computation, 2017

\section{Test of Homoscedasticity and Linearity for hypothesis two}

From the output below, there appears to be a moderate, positive correlation among the variables. Respondents that are highly affected by Organisational Creativity experience low levels of Product Quality. On the other hand, employees with less affected by Organisational Creativity experience much higher levels of Product Quality. There is no indication of a curvilinear relationship (test of linearity) and the scatter plot shows a fairly even cigar shape along its length (test ofHomoscedasticity).

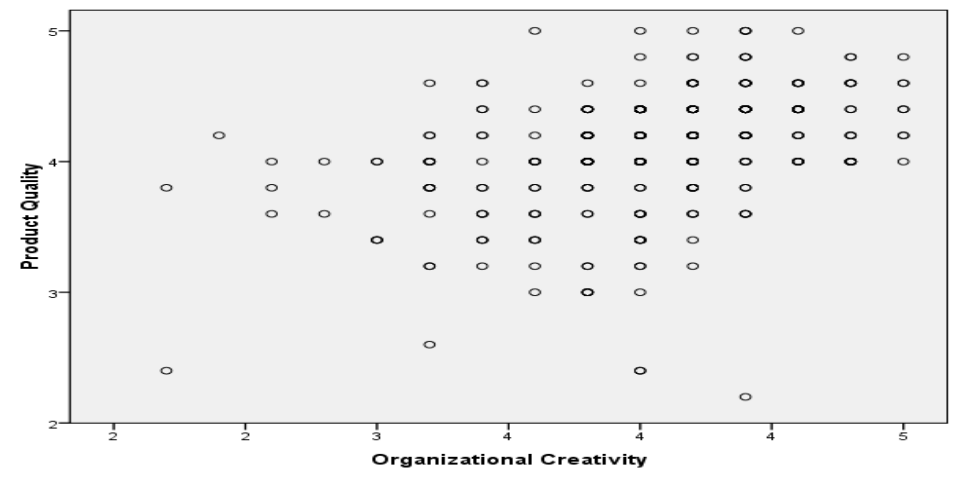

Fig 4.4.6.4: Scatter Plot of organisational creativity and product quality Scores

Source: Author's Fieldwork Computation, 2017

\section{Test for Hypothesis Two}

$\mathrm{Ho}_{2}$ : There is no significant effect of organisational creativity on product quality.

Standard multiple regression was used to explore the effect of organisational creativity on product quality. The result of regression as contained in Table: ANOVA, shows that the F-test was 22.950, significant at 1 percent $[p<.000]$. This showed that the model was well specified.

Table 3: Anova of organisational creativity on product quality

\begin{tabular}{|c|c|c|c|c|c|c|}
\hline \multicolumn{7}{|c|}{ ANOVA $^{\mathrm{b}}$} \\
\hline \multicolumn{2}{|c|}{ Model } & Sum of Squares & Df & Mean Square & $\mathrm{F}$ & Sig. \\
\hline \multirow[t]{3}{*}{1} & Regression & 14.618 & 4 & 3.654 & 22.950 & $.000^{\mathrm{a}}$ \\
\hline & Residual & 58.121 & 365 & .159 & & \\
\hline & Total & 72.738 & 369 & & & \\
\hline \multicolumn{7}{|c|}{$\begin{array}{l}\text { a. Predictors: (Constant), Organizational Creativity, idea uniqueness, competitive advantage and brand } \\
\text { expectation }\end{array}$} \\
\hline & dent Variable & oduct Quality & & & & \\
\hline
\end{tabular}

Author's Fieldwork Computation, 2017 
Also, the result of regression as contained in Table: Model Summary, shows that the R Square gave a large value of 20.1 per cent. This means that the model (which includes Organizational Creativity, idea uniqueness, competitive advantage and brand expectation) explained about 20.1 per cent of the variance in perceived product quality.

\section{Model Summary}

\begin{tabular}{|c|c|c|c|c|}
\hline Model & $\mathrm{R}$ & R Square & Adjusted R Square & Std. Error of the Estimate \\
\hline 1 & $.448^{\mathrm{a}}$ & .201 & .192 & .399 \\
\hline
\end{tabular}

Specifically, the result of regression as contained in Table: Regression Coefficients, tests the second hypothesis of this study. From the output below, a unit increase in perceived idea uniqueness scores caused about .137 unit increase in perceived product quality scores which was statistically not significant at 1 per cent with the aid of the $\mathrm{p}$ value (0.031). Based on the result, the null hypothesis is accepted; thus, there was no relationship between idea uniqueness and product quality.

Also, from the table below, a unit rise in perceived competitive advantage scores induced about .032 unit decrease in perceived product quality scores which was statistically not significant at 1 per cent going by the $\mathrm{p}$ value (0.570). Based on the result, the null hypothesis is accepted; thus competitive advantage does not affect product quality.

More importantly, a unit rise in perceived brand expectation scores induced about .090 unit increase in product quality scores which is statistically not significant at 1 per cent going by the $\mathrm{p}$ value $(0.069)$. Based on the result, the null hypothesis is accepted; thus, there was no relationship between brand expectation and product quality.

Furthermore, there was positive relationship between perceived organisational creativity and perceived product quality such that a unit rise in perceived organisational creativity scores induced about .274 unit rise in perceived product quality scores which was statistically significant at 1 per cent going by the $p$ value $(0.000)$. Based on the result, the null hypothesis is rejected; thus organisational creativity affected product quality.

Table 4.4.6.3

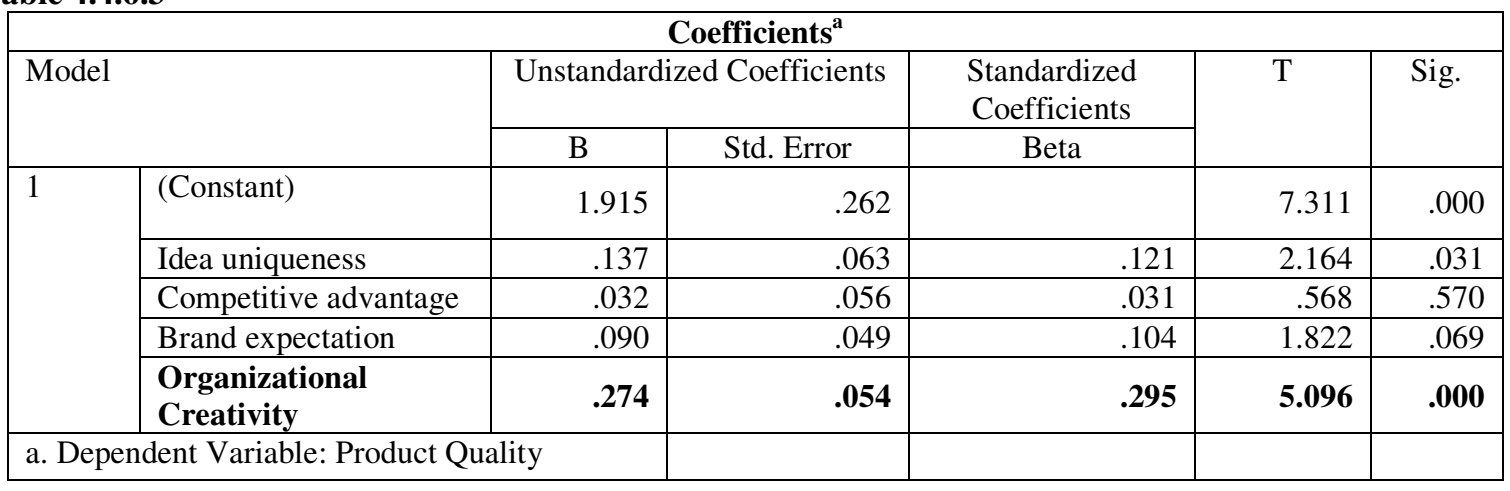

Author's Fieldwork Computation, 2017

\section{Discussion of Findings of Hypothesis One}

The findings of the study further revealed a positive relationship between Leadership initiatives in the workforce diversity management and organisational success indicates that as leadership initiatives in the workforce diversity increases, the level of organisational success tends to increase. This is in agreement with the study of McArthur (2010) which posits that leaders are expected to communicate the strategies and talk about the business goals and achievement in relation to the management of workforce diversity for the strategies identified and the company as a whole. While implementing the laid strategies, employees should be held accountable for their behaviors especially in diversity promoting behaviors that are adopted by the organisation. 


\section{Discussion of Findings of Hypothesis Two}

The positive link between organizational creativity and product quality indicates that as organizations become creative in their business practices and dealings, the more quality product they tend to produce. This is in consistence with Kimes (2001) who opined that quality has long been a mantra of the U.S lodging industry. In her studies, she maintained that countless hotel properties have spent time and money on quality assurance, benchmarking, assessing the cost of error, continuous improvement, and total quality management among other quality-related programmes and tactics. She affirmed that most quality-assurance endeavours, however, seemed to assume that quality would necessarily improve profitability.

\section{Conclusion and Recommendations}

No organisation this dispensation of globalization would survive without workforce diversity. It is expected that organizations should put in place strategies to enhance workforce diversity.The sense of social identity compels individuals to want to belong in a particular group. The challenge comes in when these groups cannot be similar or equal in terms of characteristics accorded to them. Identifying with a particular group enhances the relationship between members of such teams. Members of a group can also feel that they cannot associate with those who do not belong to their group (Kinyanjui, 2013). In organizations different groups also occur among the workforce and these can be due to gender, race ethnic background, disability and education. This diverse workforce creates room for competition that normally arises from self-interest or protecting the interests of a particular group within a workforce. The strategies used to manage this diversity are vital to utilizing the full potential of all the members of the workforce without creating conflicts. It is the duty of the management to recognize and evaluate their diversity and come up with conditions that will enhance effective workforce diversity for the benefit of the firms.

It was therefore recommended that organizations should make workforce diversity management a core business value because diverse work teams bring high value to organizations, and respecting individual differences will benefit the workforce by creating a competitive edge and increasing work productivity. The leadership should also provide directional and strategic leadership that are crucial in managing workforce diversity.

\section{References}

Afzal F, Mahmood K, \&Sajid M, (2013) "Comparison of Workforce Diversity In Public Private Business Organisations", European Journal of Business \& Management, 5(5), 109-113

Bagshaw, M, (2004) "Is diversity divisive?" Journal of Industrial and Commercial training, 36(4) 153-157.

Bryan, J.H (1999). "The diversity imperative", executive excellence, 6.

Elsaid. M. (2012). "The Effects Of Cross Cultural Diversity on Employee Performance In Egyptian Pharmaceutical Organisations", Business\& Management Research Journal 1(4): 162-179

Florida, R. (2004). America's looming creativity crisis. Harvard Business Review October, 122-136.

French, W. \& Bell, C.H (1983) Organisational Development ( $2^{\text {nd }}$ Ed.) Prentice Hall, New Delhi.

Gilson, L.L., Litchfield R., Lim H.S. \& Gilson P.W.. (2015). Creativity in teams: Directions for future research," in C.E. Shalley, M.A. Hitt, J. Zhou eds. The Oxford Handbook of Creativity, Innovation, and Entrepreneurship. Oxford University Press: New York, 177-205.

Gilson, L.L., Litchfield R., Lim H.S. \& Gilson P.W.. (2015). Creativity in teams: Directions for future research," in C.E. Shalley, M.A. Hitt, J. Zhou eds. The Oxford Handbook of Creativity, Innovation, and Entrepreneurship. Oxford University Press: New York, 177-205.

Holt, M (2010) Challenges of Diversity Management. Retrieved from http://smallbusiness.chron.com/challengesdiversity-management-3044.html

Kim, D.Y, Kumar, V. \& Kumar U (2012) Relationship between quality management practices and innovation. J OperManag 30(3):295-315.

Kimes, S.E (2001) How Product Quality Drives Profitability: The Experience at Holiday Inn (Electronic Version Cornell Hotel and Restaurant Administration Quality 42 (3),25-28. Retrieved (1 Nov, 2017).

Office of State Personnel (OSP).(2008). Diversity management initiatives. Retrieved from http://www.performancesolutions.nc.org/developmentinitiatives/diversitymanagement/diversitymanagem entinitiatives/index.asp

Okoro A \& Washington C, (2012). "Workforce Diversity \&Organisational Communication; Analysis of Human Capital and Productivity”, Journal of Diversity Management 7(1), 57-62.

Richard O.C (2000) Racial Diversity, Business Strategy, and Firm Performance; a Research Based View, Academy of Management Journal, 43(2); 164-177.

Slater, S.F, Mohr, J. \& Sengupta S (2014) Radical product innovation capability: literature review, synthesis and illustrative research propositions. J Prod InnovManag 31(3):552-566 2. 
Wentling, R.M \& Palma-Rivas,( 2000). "Current Status of diversity initiatives in selected multinational corporations", Human Resources Development Quarterly Journal, 11(1), 35-60.

Zeng, J, Phan, C.A \& Matsui, Y (2015).The impact of hard and soft quality management on quality and innovation performance: An empirical study. International Journal of Production Economics, In press 162:216-226. 